\title{
Regulación de la familia de proteínas BCL-2 en células infectadas con Chlamydia trachomatis
}

\author{
Regulation of the Bcl-2 protein family in cells infected with Chlamydia \\ trachomatis
}

Adriana Paola Jutinico Shubach¹, Alejandra Mantilla Galindo², Ruth Mélida Sánchez Mora ${ }^{3}$.

\section{Resumen}

El presente artículo revisa los mecanismos inhibitorios de la apoptosis usados por Chlamydia trachomatis (Ct) frente a la familia de proteínas Bcl-2, para lograr su supervivencia intracelular. Chlamydia trachomatis es una bacteria intracelular obligada Gram negativa responsable de la infección de transmisión sexual más común en el mundo; este microorganismo es capaz de inhibir la apoptosis de la célula huésped durante su ciclo de desarrollo, obteniendo un refugio seguro para su supervivencia.

Frente a estímulos como la infección de la célula por un patógeno, la familia de proteínas Bcl-2 regula la apoptosis por medio de la liberación del citocromo $c$ de la mitocondria para desencadenar la muerte celular programada (MCP). Ct usa diversos mecanismos de regulación antiapoptótica para sobrevivir dentro de la célula huésped; dentro de ellos se observa la secreción de proteínas tales como CPAF y CADD, la escisión de la proteína Bid, el secuestro de Bad y en general el bloqueo de proteínas pertenecientes a la familia $\mathrm{Bcl}-2$ con dominio $\mathrm{BH} 3$, que afectan directamente la vía mitocondrial ocasionando la persistencia, desarrollo y replicación de $C t$ en la célula huésped.

Palabras clave: Chlamydia trachomatis, familia Bcl-2, CPAF, CADD, vía mitocondrial.

\begin{abstract}
This article reviews the apoptosis inhibitory mechanisms used by Chlamydia trachomatis $(C t)$ against the $\mathrm{Bcl}-2$ protein family to achieve its intracellular survival. Chlamydia trachomatis $(\mathrm{Ct})$ is a Gram-negative obligate intracellular bacterium responsible for the infection of the most common sexually transmitted infection in the world; this organism is able to inhibit host cell apoptosis during development cycle, obtaining a safe survival refuge.
\end{abstract}

When exposed to stimuli such as infection of the cell by a pathogen, the Bcl-2 protein family regulates cell apoptosis by releasing cytochrome $\mathrm{c}$ from mitochondria to trigger programmed cell death (PCD). Ct uses various anti-apoptotic regulation mechanisms to survive within the host cell, some of them are: Protein secretion such as CPAF and CADD; the cleavage of Bid protein; the Bad kidnapping and in general the blocking of proteins that belong to the $\mathrm{Bcl}-2$ family with BH3 domain, these affect the cell mitochondrial pathway causing Ct persistence, development, and replication within the host cell.

Keywords: Bcl-2 family, CADD, Chlamydia trachomatis, CPAF, mitochondrial pathway.

'Bacterióloga y Laboratorista Clínico Universidad Colegio Mayor de Cundinamarca. Joven Investigadora Colciencias.

${ }^{2}$ MSc Inmunología Universidad de Cartagena- Bacterióloga y Laboratorista Clínico Universidad Colegio Mayor de Cundinamarca. Docente Universidad Colegio Mayor de Cundinamarca.

${ }^{3} \mathrm{PhD}$ Biotecnología. MSc Genética Humana. Docente Universidad Colegio Mayor de Cundinamarca.

Correspondencia: rmsanchezm@unicolmayor.edu.co

Recibido: 10/09/2015 Aceptado: 11/11/2015 


\section{Introducción}

La infección de transmisión sexual causada por Chlamydiatrachomatis $(C t)$, bacteriaGramnegativa, cursa de manera asintomática haciendo su detección inoportuna $(1,2)$; causando infertilidad, uretritis, endometriosis, enfermedad pélvica inflamatoria entre otras (1-3). Este microorganismo actúa como un parásito intracelular, ya que necesita de la maquinaria de la célula huésped para su replicación y supervivencia (4). En su ciclo bimórfico participa el cuerpo elemental (CE), que se adhiere e induce el ingreso a la célula huésped, el cuerpo reticular (CR), que utiliza los nutrientes de la célula huésped para su multiplicación y diferenciación en más CE (1). Gracias a este ciclo Ct evade la respuesta inmune del organismo, además de secretar proteasas en el citoplasma de la célula huésped, para inhibir los procesos de muerte celular o apoptosis (5).

Una de las proteasas secretadas es el factor de actividad proteasomal (CPAF), que degrada las proteínas proapoptóticas del dominio único $\mathrm{BH} 3$, de la familia de proteínas Bcl-2. Estas proteínas intervienen en la vía de señalización mitocondrial, cuya activación se da por la liberación del citocromo $c$ que desencadena una cascada y finaliza en la apoptosis de la célula infectada $(3,6-8)$. Otra proteasa es conocida como "proteína de Chlamydia asociada a receptores de muerte" (CADD), que se expresa al final del ciclo de infección de $C t y$ posee una región de dominio de muerte (9). Por lo descrito anteriormente, el propósito de este artículo es revisar los mecanismos inhibitorios de la apoptosis usados por $C t$ frente a la familia de proteínas Bcl2 , para lograr su supervivencia intracelular.

\section{Generalidades de Chlamydia sp.}

Las Chlamydias sp. son microorganismos pertenecientes al orden Chlamydiales, familia Chlamydiaceae (10); y género Chlamydia, el cual tiene cuatro especies, dentro de ellas Chlamydia trachomatis (Ct) (11). La Ct es una bacteria Gram negativa intracelular obligada $(7,8)$ que causa la infección bacteriana de transmisión sexual (ITS) más común en el mundo; encontrando con cerca de 92 millones de casos de infección al año (2,12-14). Existen distintas serovariedades: las causantes de tracoma (A-C), causantes de infecciones transmitidas por vía sexual (D-K) y las que causan linfogranuloma venéreo "LGV" (L1-L2-L3) $(15,16)$.

Ct tiene un ciclo bimórfico, que inicia con la adherencia a la célula huésped de la partícula metabólicamente inactiva conocida como cuerpo elemental (CE), la cual ingresa a través de adhesinas bacterianas tales como los glicosaminoglicanos (GAG), proteínas de membrana externa (MOMP), $\mathrm{OmcB}$ y PmpD, entre otros $(2,17,18)$; este $\mathrm{CE}$ hace una diferenciación formando la partícula metabólicamente activa o cuerpo reticular (CR) que es la forma intracelular, que impide que el fagosoma se fusione con el lisosoma evitando ser destruido por las enzimas (19). Dentro de la célula huésped se forma una inclusión en donde posteriormente los CR se dividen por fisión binaria y se reorganizan nuevamente en la progenie de CE que se liberaran por lisis celular y así logran la infección de nuevas células, Figura 1. $(10,15,20)$.

Dentro de las manifestaciones clínicas se incluyen cervicitis, uretritis, enfermedad pélvica inflamatoria (EPI), abortos e infertilidad; y además se conoce que también afecta a hombres y niños $(11,22)$. Dentro de los factores de riesgo asociados a la infección por $C t$ se encuentran la edad, la raza y las condiciones socioeconómicas; un mayor número de parejas sexuales, una nueva pareja sexual, la falta de uso de métodos anticonceptivos de barrera y la infección gonocócica concurrente también está asociado de manera consistente con las infecciones por este patógeno (11).

\section{Muerte celular programada}

La muerte celular programada (MCP) es el mecanismo responsable del equilibrio y la proliferación celular de tejidos sometidos a un recambio; además de ejercer un papel en el mecanismo de defensa, 


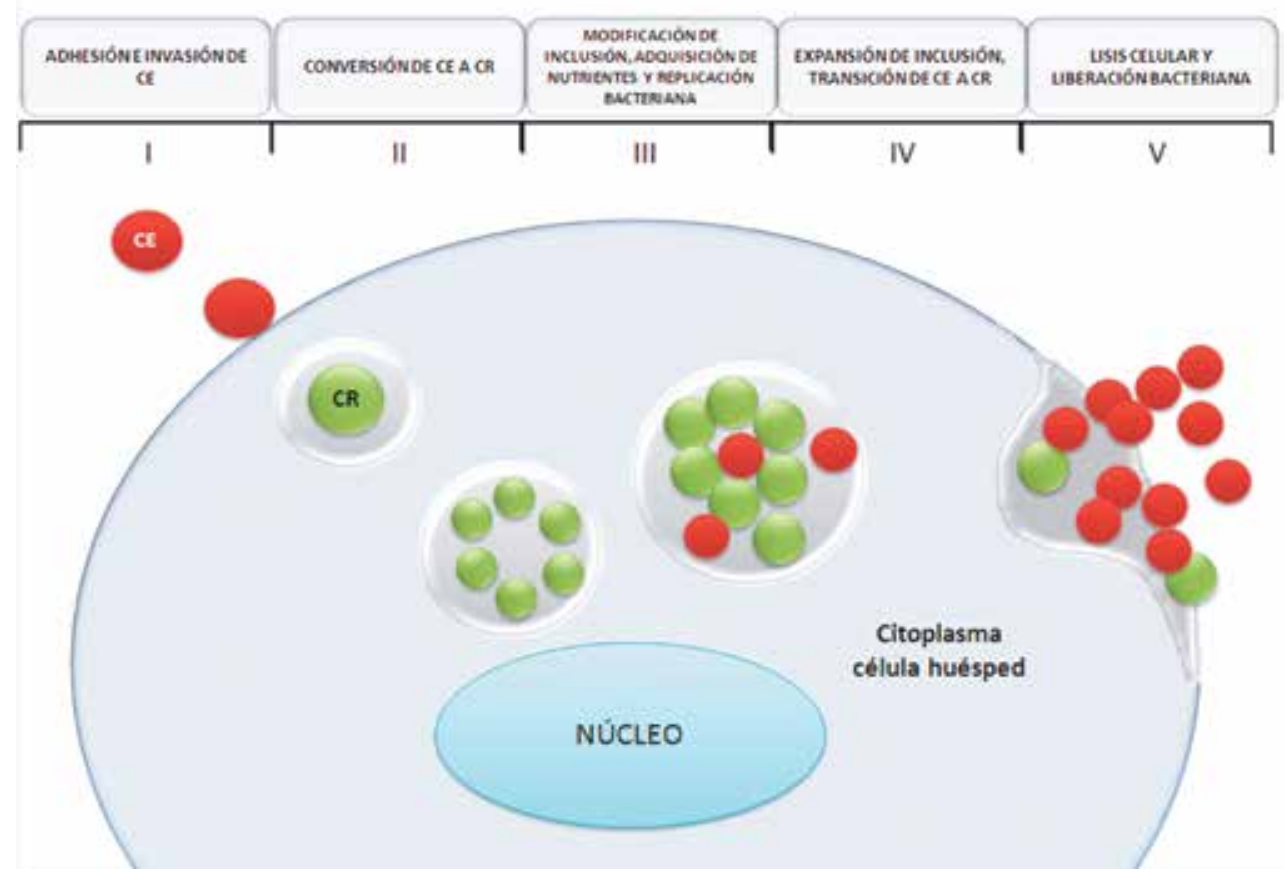

Figura 1. El ciclo de vida de Chlamydia trachomatis, inicia con la adhesión de la partícula metabólicamente inactiva o cuerpo elemental (CE) a la célula huésped, para luego iniciar la conversión a la partícula metabólicamente activa o cuerpo reticular (CR) que estará presente en una inclusión para luego producir y liberar nuevos CE. Tomado y modificado de J.L. Cocchiaro $(20,21)$.

cuando hay una alteración del ciclo celular o un proceso infeccioso activo (23). Rudolf Ludwig Karl Virchow en 1858 clasificó los procesos de MCP en degeneración, mortificación y necrosis; en 1879 introdujo los términos Karyorhesis y Karyolysis haciendo referencia a la desintegración y desaparición del núcleo. Ya en 1972 John F. Kerr y colaboradores implantaron el término apoptosis, haciendo referencia a "la caída de las hojas de los árboles en otoño y los pétalos de las flores” $(18,24)$.

Existen dos tipos de MCP: 1) la patológica o necrosis, caracterizada por la ruptura celular y 2) la fisiológica o apoptosis, que ocurre durante a homeostasis del organismo para mantener la integridad de la célula (18). En la necrosis, las células que mueren se hinchan y lisan causando inflamación por la liberación de su contenido al espacio extracelular; y por otro lado las células que atraviesan por un proceso apoptótico presentan cambios morfológicos de ADN, haciendo que la célula se encoja y se divida en fragmentos o cuerpos apoptóticos que son fagocitados por macrófagos o células adyacentes para su eliminación eficaz $(19,24)$.

La MCP se encuentra regulada por diversas vías de señalización (25): la primera es la vía extrínseca o de receptor de muerte, que ocurre en células tipo I, y se produce por la estimulación de receptores de superficie (Fas/Apo1/CD95 o TNFR) con sus ligandos afines (1). Mediante la porción citoplasmática de dichos receptores, se genera una seńal que activa las caspasas, tal como la caspasa 8 , esta a su vez activa la caspasa- 3, conduciendo la MCP (19).

La segunda vía es en las células tipo II, en donde se requiere la amplificación de la señal por vía mitocondrial ó vía intrínseca. Si la membrana mitocondrial se permeabiliza, los factores apoptogénicos como el citocromo $c$, el Smac/Diablo y AIF se liberan en el citosol para activar la cascada de caspasas. La permeabilización de la membrana mitocondrial está bajo el control de proteínas miembros de la familia Bcl-2, que se caracterizan 
por tener cuatro dominios de homología (BH 1-4). Las proteínas de dominio $\mathrm{BH} 3$, actúan como un censor de daño en las células y activan las proteínas Bax/Bak para permeabilizar la membrana mitocondrial. Las proteínas $\mathrm{Bcl}-2$, MCL 1, Bcl-XL, Bcl-w y A1; son reguladoras o antiapoptóticas. La proteína Bid, se encuentra inactiva en el citosol y una vez se une a la caspasa-8 da paso a la liberación del citocromo c $(25,26)$.

Una tercera vía consiste en la apoptosis mediada por linfocitos $\mathrm{T}$ citotóxicos, quienes liberan perforina /granzima B cuando reconocen las células portadoras de antígeno (25), Figura 2.

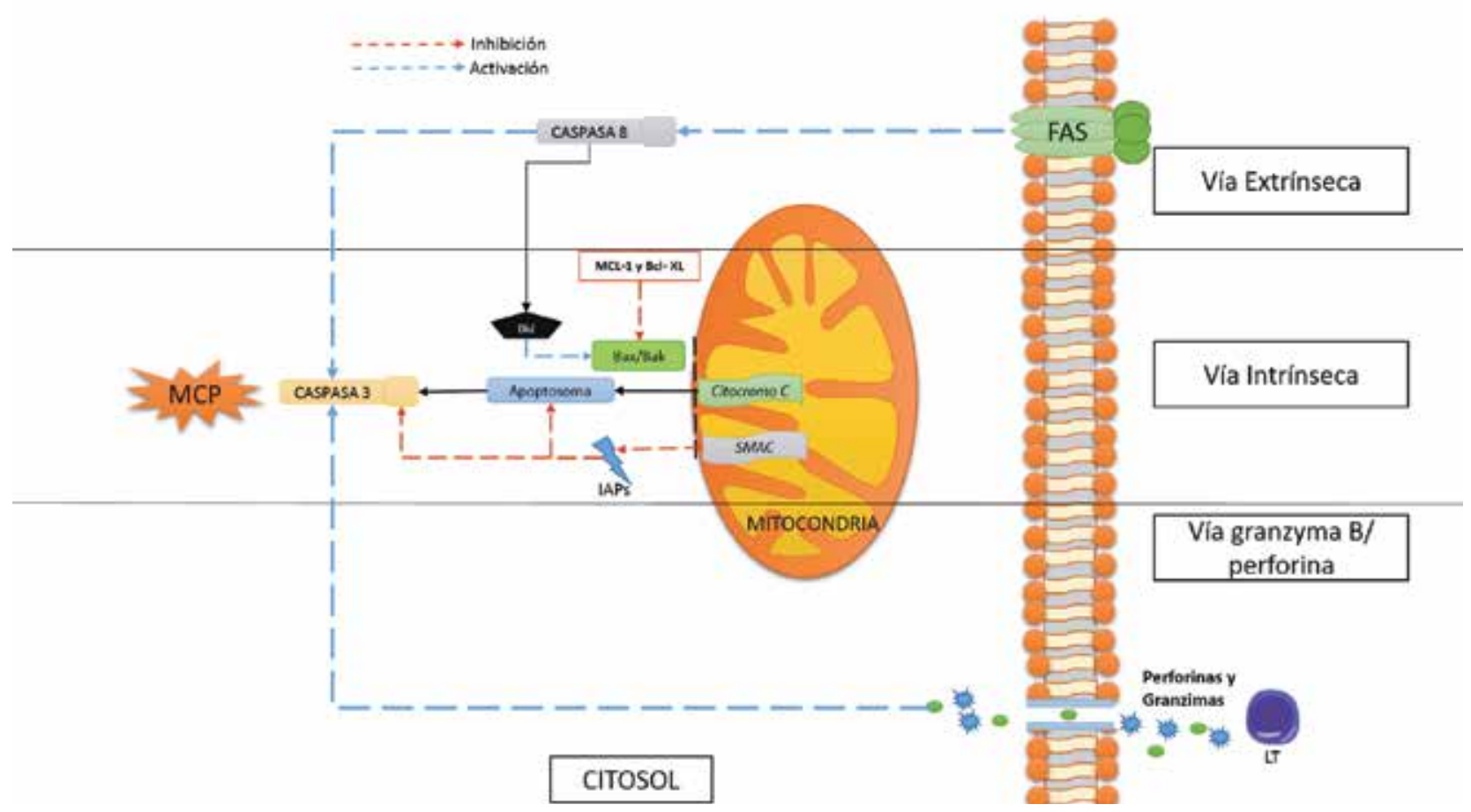

Figura 2. Muerte celular programada. En la imagen se observa las tres vías de señalización, a) la vía intrínseca, donde participan receptores de superficie como Fas, b) la vía extrínseca, que permite la liberación del citocromo $C$ y c) la vía donde hay liberación de perforinas y granzimas por parte del linfocito T. Tomado de y modificado de M. Sharma (25).

\section{Familia de proteínas $B c l-2$}

Las Bcl-2, B-cell lynphoma 2, son una familia de proteínas cuya función es regular los procesos de permeabilización mitocondrial en la vía intrínseca de la apoptosis celular; otras funciones son de dimerización, actividad de formación del poro y creación de enlaces a otras proteínas $(27,28)$. Este grupo de proteínas se caracteriza por tener cuatro dominios de homología estructuralmente conservados: $\mathrm{BH} 1, \mathrm{BH} 2$ y $\mathrm{BH} 3$ los cuales se requieren para interaccionar con otros miembros de la familia $\mathrm{Bcl}-2$, mientras que el dominio $\mathrm{BH} 4$, media las funciones de control del ciclo celular (29).

En general el proceso inicia con la activación de miembros de la familia $\mathrm{Bcl}-2$ proapoptóticos que se encuentran en el citosol para llevar a cabo la liberación del citocromo $c$, paso central de la apoptosis mitocondrial; que a su vez se une a Factor 1 activador de la proteasa apoptótica ó APAF-1 y la caspasa-9 como parte de un complejo conocido como apoptosoma (26,30). El apoptosoma regula proteínas tales como SMAC/Diablo que también 
se liberan de la mitocondria e interfiere en la acción de los inhibidores de las proteínas de apoptosis (IAP) (31), y presentan un dominio BIR, el cual es responsable de la unión directa de los IAP a las caspasas, confiriendo la capacidad antiapoptótica de las mismas $(25,28)$.

La familia de proteínas Bcl-2 se compone de tres grupos basados en su estructura y función: a) las Proteínas anti-apoptóticas, que contienen por lo general los cuatro dominios de homología. Dentro de este grupo se encuentra Bcl-XL, Bcl-w, MCL-1 y A1 que contrarrestan el proceso a través de la unión directa a las proteínas con dominio único BH3. MCL-1 y Bcl- XL se encuentran unidos a
Bak, una vez liberan esta proteína se induce la apoptosis $(1,28,32)$. b) Las proteínas pro-apoptóticas Bax/Bak ó proteínas efectoras multidominio, comparten homología en los dominios BH 1-3. Bax, presente como monómero en el citosol y señales de daño se somete a un cambio conformacional que junto con Bak, presente al interior de la mitocondria, permiten la liberación del citocromo $c$ de la mitocondria para generar la MCP (32). c) Las proteínas de dominio único $\mathrm{BH} 3$ que comparten homología únicamente en el dominio cortó $\mathrm{BH} 3$, vigilan el bienestar de la célula y se activan en respuesta a señales de estrés (33), siendo las más relacionadas con el mecanismo de supervivencia de la Ct en las células huésped, Figura 3.

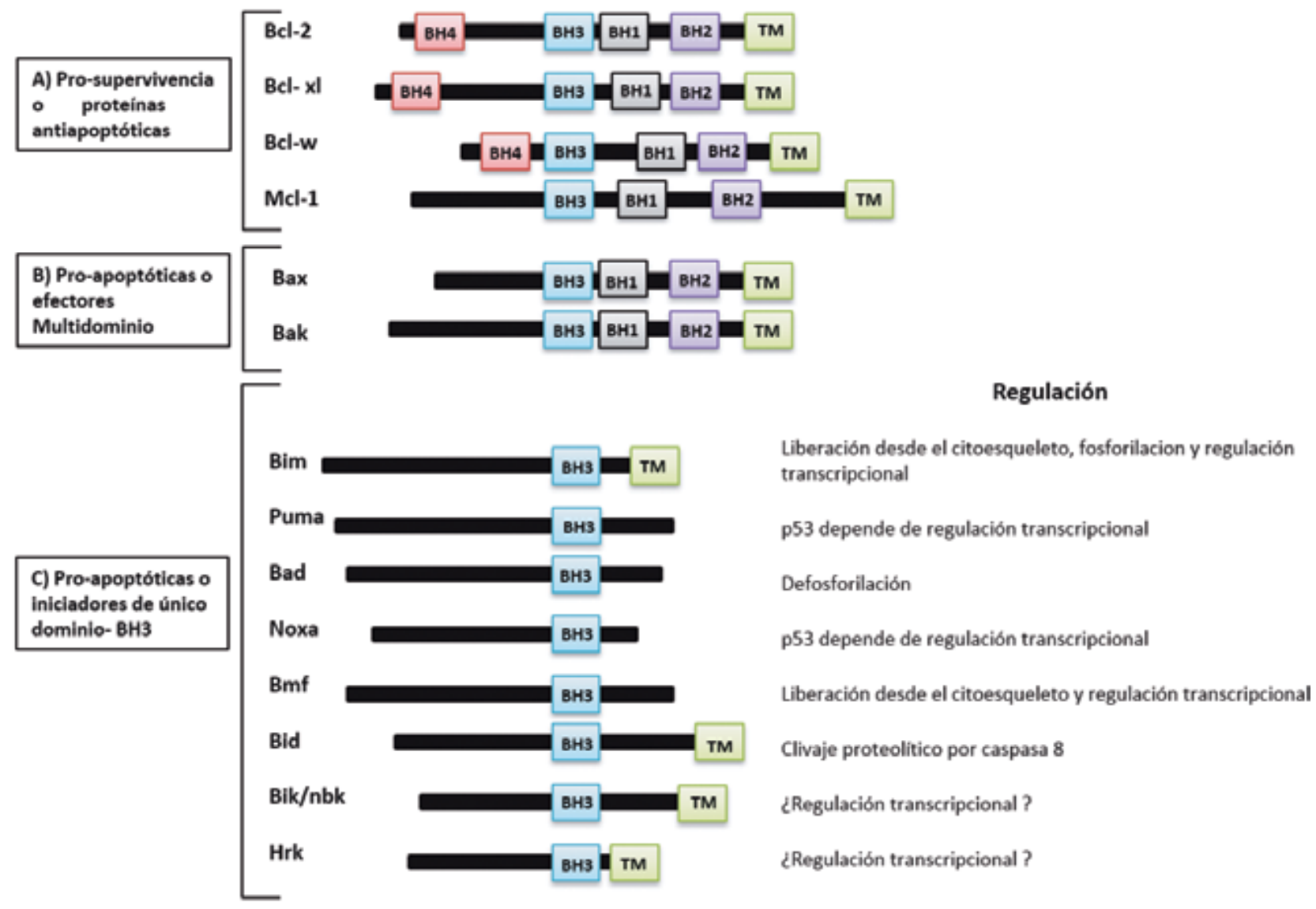

Figura 3. Dominios de familia de proteínas Bcl-2 y clasificación según su función: Se observan A) las proteínas de prosupervivencia o antiapoptóticas que pueden tener los 4 dominios; las proteínas pro-apoptóticas como los B) efectores multidominio, que permiten la liberación del Citocromo $C$; y C) los iniciadores de único dominio $\mathrm{BH} 3$ para la regulación de la apoptosis. Tomado y modificado de $\mathrm{S}$. Ying (1). 


\section{Proteínas de dominio único $\mathrm{BH} 3$}

Las proteínas de dominio único $\mathrm{BH} 3$ pueden transmitir señales de muerte a la mitocondria, ya sea por la inhibición de miembros anti-apoptóticos de Bcl-2 o la activación de miembros pro-apoptóticos de varios dominios como Bax y Bak (31;34). Estas proteínas se clasifican en dos subgrupos: los "activadores" de Bax y presumiblemente de Bak, que son Bim, Bid y Puma; y los "sensibilizadores" o "depresores" como Bad y Noxa, que alejan los activadores de Bax $(27,32,35)$. Bim es un activador de apoptosis en potencia, ya que se une a diversas proteínas incluyendo las anti-apoptoticas MCL-1 y Bcl-XL, liberando así a Bak de su secuestro (32), Figura 4.

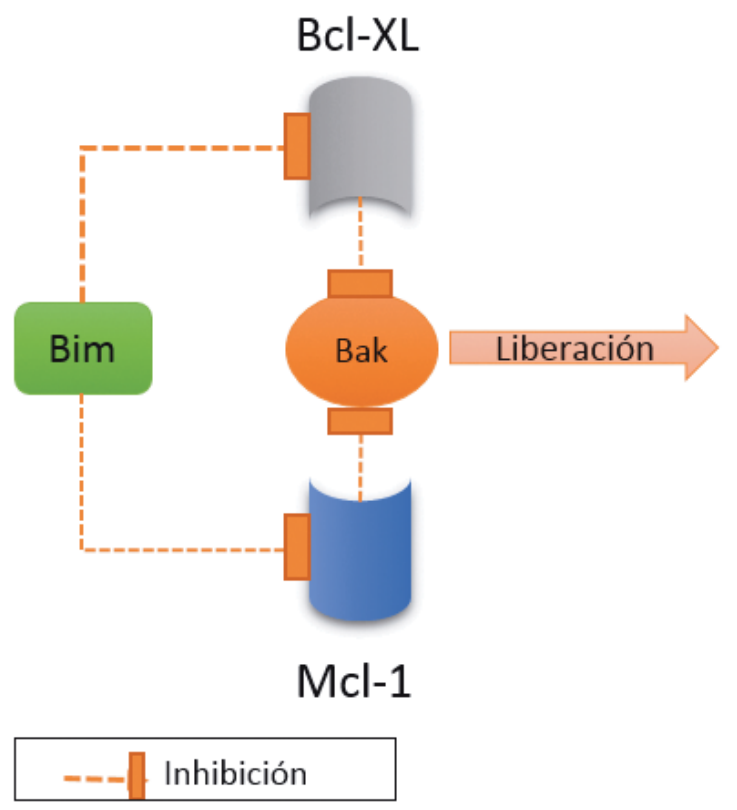

Figura 4. Modelo para la activación de bax/bak: Se observa como Bim, proteína de único dominio BH3, inhibe la a Bcl-XL y Mcl-1, para permitir la liberación de Bak y liberar el Citocromo $C$. Tomado y modificado de Fletcher (32).

Algunas proteínas son activadas por daño de ADN, como Puma, Noxa y Bim que son dependientes de la activación del supresor tumoral p53 (1;35). Puma es un mediador esencial independiente de la apoptosis in vivo (36). Otras proteínas se activan a partir de su liberación en los sitios de captura como por ejemplo Bim y Bmf quienes permanecen en el citoesqueleto inactivas y cuando son liberadas permiten la unión e inactivación de los factores antiapoptóticos (37). Bim ayuda a la movimiento de los microtúbulos y junto con Puma retira las citocinas de los linfocitos (1, 38) para activar directamente a Bax (32). Otro tipo de activación se realiza por desfosforilación de Bad que es regulada por la vía de señalización PI3K-AKT (35). Esta proteína es desfosforilada en ausencia de señales de supervivencia, lo que le permite distanciarse de la proteína citosólica adaptadora 14-3-3 $\beta$ y migrar a la mitocondria para promover la apoptosis de la célula (1). Finalmente la activación se puede dar por escisión proteolítica como en el caso de Bid, que presenta una forma bioactiva truncada (tBid) la cual se escinde proteolíticamente por la división de la caspasa 8 , ayudando a ampliar el proceso de muerte celular (1,32).

\section{Chlamydia y apoptosis}

Ct es capaz de inhibir e inducir apoptosis en la célula huésped bajo diversas condiciones de estrés, tales como la privación de nutrientes o el tratamiento con interferón gamma (1); cuando esta bacteria entra en un modo no-productivo de crecimiento se llama persistencia, en el que la actividad metabólica continúa pero las células dejan de dividirse, inhibiendo las vías de señalización de la apoptosis durante su ciclo, $\mathrm{y}$ ofreciendo un refugio seguro para su supervivencia en la célula huésped (31).

La supervivencia de las células infectadas con $C t$ se ve favorecida a través de la inhibición de la vía intrínseca de la apoptosis, mediante la inhibición de la liberación del Citocromo $c$, en donde se encuentran involucradas la familia de proteínas Bcl-2 $(1,31)$ y la regulación de ello es temporal para evitar la muerte celular en etapas tempranas de infección; sin embargo, induce la muerte de la célula al final de su ciclo de vida $(2,19,32)$. Estudios realizados por Tao Fan y colaboradores, encontraron la disminución de la apoptosis de células HeLa infectadas con $C t$, aún expuestos a ciertos inductores de apoptosis tal como la estaurospoina (39). Por otra parte, se ha demostrado que las células epiteliales o monocitos infectados con $C t$ presentan protección contra la MCP depen- 
diente de la vía mitocondrial, pero no cuando la vía extrínseca es activada $(40,41)$, también se ha propuesto que $C t$ secreta proteínas para inhibir la MCP.

Dentro de las moléculas que $C t$ secreta, para inhibir la MCP, se encuentra la "proteína de Chlamydia asociada con receptores de muerte (CADD)", que se expresa al final del ciclo de infección y posee una región de dominio de muerte que le permite interactuar con el ligando Fas, el cual es reclutado por la inclusión de Chlamydia, inhibiendo la apoptosis inducida por Fas (9). Por otro lado, también se ha demostrado como $C t$ secreta la proteína CPAF, degrada y escinde proteínas de dominio único $\mathrm{BH} 3$ de la familia BCL-2 para protegerse de la apoptosis y poder sobrevivir en la célula huésped.

\section{CPAF protege a Chlamydia trachomatis de la apoptosis}

En $C t$ se ha estudiado un sistema de inyección molecular de proteínas denominado sistema de secreción tipo III, que modula la apoptosis (1). En este microorganismo se ha descrito el factor de actividad proteosomal o CPAF, que es una proteína conservada entre las diferentes especies de Chlamydias, secretada en el citosol de la célula huésped y que cuenta con dos subunidades un cimógeno catalítico inactivo, que por dimerización se convierte en la forma activa $(9,12,30,42)$.

Dentro de sus funciones se han descrito: el clivaje de factores de transcripción como el factor regulador X5 ó RFX5, requerido para la presentación de antígeno; la estimulación del factor de transcripción USF-1, que permite la expresión de antígenos por el complejo mayor de histocompatibilidad; la ruptura de la citoqueratina $8(\mathrm{Ck}-8)$, vital para la expansión de la inclusión de Ct (9); y la señalización de proteínas proapotóticas con dominio $\mathrm{BH} 3$ expuestas para su degradación $(9,43)$. Una inhibición prolongada de CPAF conduce a la pérdida de la integridad de la inclusión de $\mathrm{Ct}$, además de la activación de la caspasa -1, que finalmente lleva a la MCP. Por lo tanto, el desarrollo de inhibidores específicos de la proteasa CPAF podría ser una atractiva estrategia terapéutica anti-Chlamvdial (42), Figura 5.

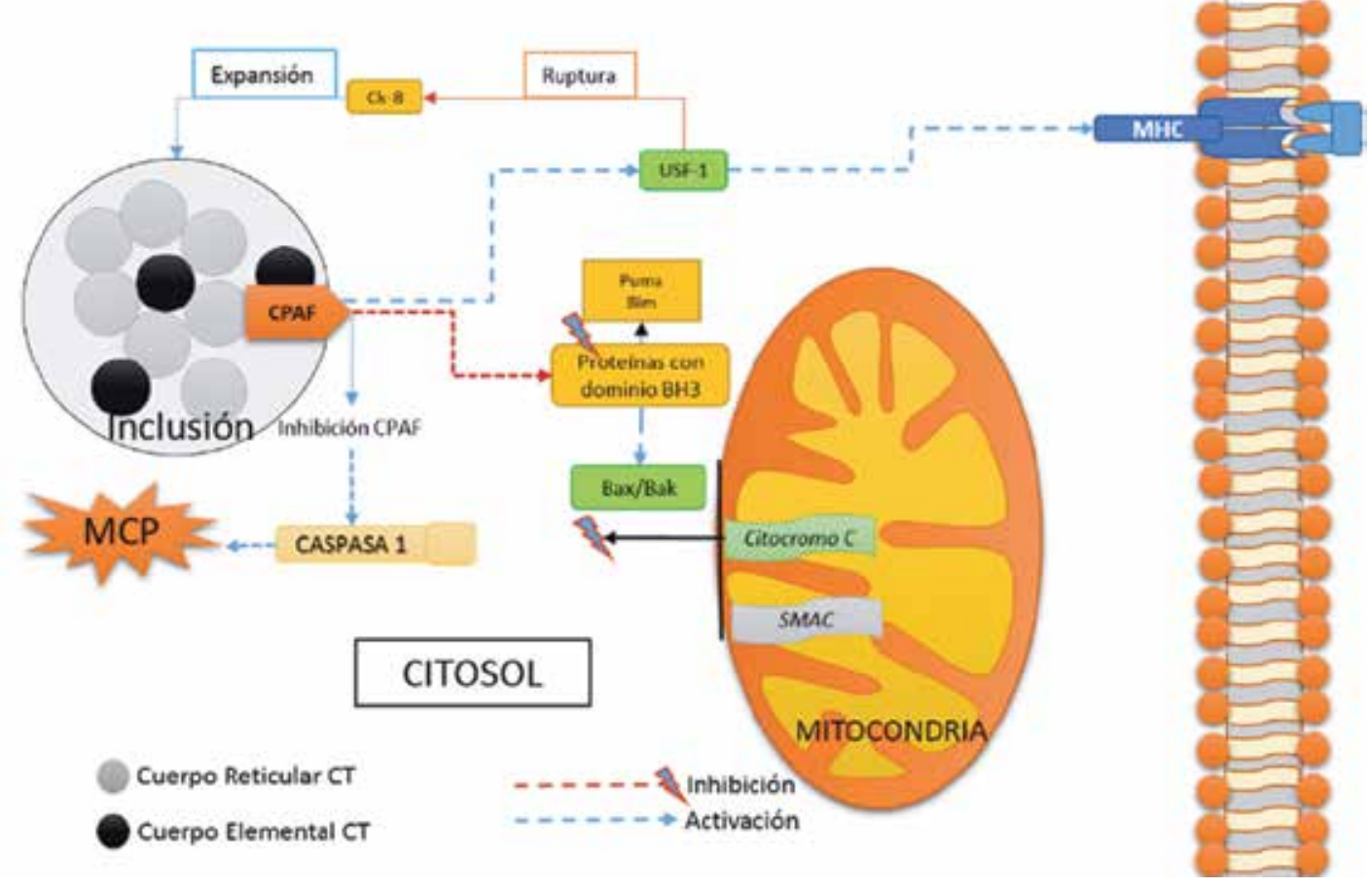

Figura 5. Factor de actividad proteosomal de Chlamydia trachomatis: Se muestra como CPAF estimula el factor de transcripción USF1 que funciona en la presentación de antígenos, junto con RFX5, a través del complejo mayor de histocompatibilidad (MHC). También degrada las proteínas pro-apoptóticas de dominio $\mathrm{BH} 3$ para contrarrestar la muerte celular, y que la inclusión permanezca intacta. 


\section{Papel de las proteínas de la familia Bcl-2 en cé- lulas infectadas con $\boldsymbol{C t}$.}

Como se ha mencionado a lo largo de este artículo, Ct utiliza mecanismos eficientes para bloquear la liberación de Citocromo $c$ de la mitocondria (30) y su actividad inhibidora frente a la apoptosis se centra en las proteínas de dominio $\mathrm{BH} 3$ (1). Como se observa en la figura No 3 , todas las proteínas proapoptóticas comparten un pequeño dominio $\mathrm{BH} 3$ y su eliminación es necesaria para la orientación de la degradación durante la infección (1). Ct activa la proteína CPAF, responsable de la orientación de las proteínas con una exposición de dominio $\mathrm{BH} 3$ para su degradación $(30,34,44)$ lo que conlleva a que las señales de muerte no puedan ser transmitidas a la mitocondria, lo que explica el bloqueo de la apoptosis (25).

Por otro lado, en células tipo II infectadas por $C t$ se inhibe la vía mitocondrial (1), en donde participa la proteína Bid, esta es activada por la caspasa-8 quien la escinde para generar una forma truncada denominada tBid, la cual expone el dominio $\mathrm{BH} 3$, que activará a Bax para liberar el Citocromo c (45-46). tBid está destinada a la degradación durante la infección, lo que sugiere que la actividad de degradación de Ct es específica (1).

Asimismo, una de las principales vías de supervivencia intracelular se conoce como la vía de la PI3-quinasa (5). La PI3-quinasa fosforila al fosfolípido de membrana PIP 2 para formar $\mathrm{PIP}_{3}$ y así activar la proteína serina/treonina quinasa Akt. A continuación, Akt fosforila a un cierto número de proteínas que regulan la apoptosis con la ayuda de Bad. Para evitar la MCP, Bad es fosforilada, lo que permite su secuestro en el citosol (26) y co-localización por la proteína 14$3-3 \beta$ sobre la inclusión de $C t$ para ser reclutada por la proteína IncG (1).

\section{A manera de conclusión}

En Colombia son pocas las investigaciones básicas que se realizan en $C t$, siendo este uno de los principales microorganismo a nivel mundial causante de enfermedades de transmisión sexual, que causa enfermedad pélvica inflamatoria, muertes por parto prematuro y tracoma (2). Ct inhibe la apoptosis como un mecanismo de supervivencia (39) demostrado por Ying, S. y colaboradores en el 2007; observando que aún bajo estímulos apoptóticos, son resistentes a la apoptosis, por lo que se sugiere que uno de los mecanismos de supervivencia que utiliza Ct durante la primera etapa de la infección en la célula huésped es la secreción de proteasas como la CPAF (1). Esta proteasa actúa sobre proteínas de la familia Bcl-2 y especialmente en las proteínas pro-apoptoticas de dominio único BH3 (43) quienes son degradadas para evitar la activación de Bax, regulador de la permeabilidad de la membrana mitocondrial (39).

Desde 1998, Fan, T. y colaboradores observaron que durante los mecanismos de degradación de proteínas existen cambios masivos de los orgánulos como la dilatación y vacuolización del retículo endoplásmico (39); en el año 2006 por Ying S y compañeros se mencionan también la distorsión de las mitocondrias, y la condensación nuclear en la etapa tardía de la infección en la célula, cambios que no son típicos de la muerte celular (44).

Como se ha descrito, Ct usa mecanismos para interferir en la liberación del Citocromo $c$, que induciría la apoptosis gracias a la activación de la cascada de caspasas; sin embargo en el 2001, Fischer S., analizó el grado de inhibición de la apoptosis en las células infectadas, encontrando la resistencia a la apoptosis y a la activación de la caspasa-3 aun cuando se trataron las células infectadas con $\mathrm{Ci}$ tocromo $c$; lo que indica que este microorganismo no sólo bloquea la vía intrínseca, si no también controla cada vía de señalización (47). Ct no es el único microorganismo que cuenta con diferentes 
mecanismos de superviviencia celular; en el 2004 G. Byrne describió que existen algunos sistemas de secreción de proteínas sobre el citoplasma usados por algunos microorganismos como Shigella sp., Rickettsia rickettsii inhiben la apoptosis a través de la inducción del factor nuclear-kB (NF-kB) (44). También existen otras formas de inhibición que han sido estudiadas como la producción de toxinas bacterianas que inhiben la síntesis de proteínas de la célula huésped en el caso del Corynebacterium spp y Shigella sp. (31).

Actualmente en la Universidad Colegio Mayor de Cundinamarca, Bogotá-Colombia, en el grupo de investigación de Biotecnología y Genética UCMC, pretende profundizar el estudio e investigación básica de $C t$, con el fin aclarar los mecanismos que pueden estar utilizando estos microorganismos para causar esta infección crónica persistente e inhibir las vías apoptóticas; teniendo en cuenta que esta enfermedad, que aunque común, es poco conocida por la población en general.

\section{Referencias}

1. Ying S, Pettengill M, Ojcius DM, Hacker G. Host-Cell Survival and Death During Chlamydia Infection. Curr Immunol Rev 2007;3(1):31-40.

2. Cocchiaro JL, Valdivia RH. New insights into Chlamydia intracellular survival mechanisms. Cell Microbiol 2009 Nov;11(11):1571-8.

3. Huang Z, Feng Y, Chen D, Wu X, Huang S, Wang X, et al. Structural basis for activation and inhibition of the secreted chlamydia protease CPAF. Cell Host Microbe 2008 Dec $11 ; 4(6): 529-42$.

4. Abdelrahman YM. The chlamydial developmental cycle. 2005 Nov.

5. Verbeke P, Welter-Stahl L, Ying S, Hansen J, Hacker G, Darville $\mathrm{T}$, et al. Recruitment of BAD by the Chlamydia trachomatis vacuole correlates with host-cell survival. PLoS Pathog 2006 May;2(5):e45.

6. Ambrosini G, Adida C, Altieri DC. A novel anti-apoptosis gene, survivin, expressed in cancer and lymphoma. Nat Med 1997 Aug;3(8):917-21.

7. Sharma J, Dong F, Pirbhai M, Zhong G. Inhibition of proteolytic activity of a chlamydial proteasome/protease-like activity factor by antibodies from humans infected with Chlamydia trachomatis. Infect Immun 2005 Jul;73(7):4414-9.
8. Espinoza M. Apoptosis, muerte celular fisiológica, reseńa histórica y actualidad. Revista de Educación en biología 16[2], 153-160. 2014. Ref Type: Journal (Full)

9. Stenner-Liewen F, Liewen H, Zapata JM, Pawlowski K, Godzik A, Reed JC. CADD, a Chlamydia protein that interacts with death receptors. J Biol Chem 2002 Mar 22;277(12):9633-6.

10. Barnes RC. Laboratory diagnosis of human chlamydial infections. Clin Microbiol Rev 1989 Apr;2(2):119-36.

11. Black CM. Current methods of laboratory diagnosis of Chlamydia trachomatis infections. Clin Microbiol Rev 1997 Jan;10(1):160-84.

12. Chen AL, Johnson KA, Lee JK, Sutterlin C, Tan M. CPAF: a Chlamydial protease in search of an authentic substrate. PLoS Pathog 2012;8(8):e1002842.

13. Broadbent A, Horner P, Wills G, Ling A, Carzaniga R, McClure M. HIV-1 does not significantly influence Chlamydia trachomatis serovar L2 replication in vitro. Microbes Infect 2011 Jun;13(6):575-84.

14. Gallegos G, Ramos B, Santiso R, Goyanes V, Gosalvez J, Fernandez JL. Sperm DNA fragmentation in infertile men with genitourinary infection by Chlamydia trachomatis and Mycoplasma. Fertil Steril 2008 Aug;90(2):328-34.

15. Pérez JA, Storz J. Género Chlamydia: biología básica, propiedades antigénicas y potencial patogénico. Ciencia vetrinaria 4, 37-60. 1987. Ref Type: Journal (Full)

16. Kubo T, Ishida K, Matsuo J, Nakamura S, Hayashi Y, Sakai $\mathrm{H}$, et al. Chlamydia trachomatis serovar L2 infection model using human lymphoid Jurkat cells. Microb Pathog 2012 Jul;53(1):1-11.

17. Su H, Raymond L, Rockey DD, Fischer E, Hackstadt T, Caldwell HD. A recombinant Chlamydia trachomatis major outer membrane protein binds to heparan sulfate receptors on epithelial cells. Proc Natl Acad Sci U S A 1996 Oct 1;93(20):11143-8.

18. Kerr JF, Wyllie AH, Currie AR. Apoptosis: a basic biological phenomenon with wide-ranging implications in tissue kinetics. Br J Cancer 1972 Aug;26(4):239-57.

19. Miyairi I, Byrne GI. Chlamydia and programmed cell death. Curr Opin Microbiol 2006 Feb;9(1):102-8

20. Cervantes E. Infecciones causadas por Chlamydia trachomatis. RevFac Med UNAM 52[1], 18-22. 2009. Ref Type: Journal (Full)

21. Harvey R, Champe P, Fisher B. Microbiología. 2 ed. España: wolters klumer lippincot; 2008.

22. Arráiz N, Marcucci R, Urdaneta B, Colina S, Romero Z. Diagnóstico moelcular en la evaluación de infecciones urogenitales por Chlamydia trachomatis. Revista de Obstetricia y Ginecología de Venezuela 2008;68(00487732):195-201.

23. Jeong SY, Seol DW. The role of mitochondria in apoptosis. BMB Rep 2008 Jan 31;41(1):11-22.

24. Lawen A. Apoptosis-an introduction. Bioessays 2003 Sep;25(9):888-96. 
25. Sharma M, Rudel T. Apoptosis resistance in Chlamydia-infected cells: a fate worse than death? FEMS Immunol Med Microbiol 2009 Mar;55(2):154-61.

26. Cooper G, Hausman R. La célula. 5 ed. 2007.

27. Labi V, Grespi F, Baumgartner F, Villunger A. Targeting the Bcl-2-regulated apoptosis pathway by $\mathrm{BH} 3$ mimetics: a breakthrough in anticancer therapy? Cell Death Differ 2008 Jun;15(6):977-87.

28. Sousa R, Puy D. Histomorfometría, la apoptosis (Bcl-2 y Bax) y el marcador marcador de proliferación celular Ki-67 en neoplasias Intraepitelial cervical Universidad Federal de Minas Gerais; 2011.

29. Jeffers JR, Parganas E, Lee Y, Yang C, Wang J, Brennan J, et al. Puma is an essential mediator of p53-dependent and -independent apoptotic pathways. Cancer Cell 2003 Oct;4(4):321-8.

30. Fischer SF, Vier J, Kirschnek S, Klos A, Hess S, Ying S, et al. Chlamydia inhibit host cell apoptosis by degradation of proapoptotic BH3-only proteins. J Exp Med 2004 Oct 4;200(7):905-16.

31. Byrne GI, Ojcius DM. Chlamydia and apoptosis: life and death decisions of an intracellular pathogen. Nat Rev Microbiol 2004 Oct;2(10):802-8.

32. Fletcher JI, Huang DC. BH3-only proteins: orchestrating cell death. Cell Death Differ 2006 Aug;13(8):1268-71.

33. Puthalakath H, O’Reilly LA, Gunn P, Lee L, Kelly PN, Huntington ND, et al. ER stress triggers apoptosis by activating BH3-only protein Bim. Cell 2007 Jun 29;129(7):1337-49.

34. Ying S, Seiffert BM, Hacker G, Fischer SF. Broad degradation of proapoptotic proteins with the conserved Bcl-2 homology domain 3 during infection with Chlamydia trachomatis. Infect Immun 2005 Mar;73(3):1399-403.

35. Labi V, Erlacher M, Kiessling S, Villunger A. BH3-only proteins in cell death initiation, malignant disease and anticancer therapy. Cell Death Differ 2006 Aug;13(8):1325-38.

36. Gallenne T, Gautier F, Oliver L, Hervouet E, Noel B, Hickman JA, et al. Bax activation by the $\mathrm{BH} 3$-only protein Puma promotes cell dependence on antiapoptotic Bcl-2 family members. J Cell Biol 2009 Apr 20;185(2):279-90.
37. Ortiz G. Mecanismos moleculares que regulan la sensibilidad de células tumorales de mama a la apoptosis por TRAIL Instituto de parasitología y biomedicina de granada; 2005.

38. Starr TK, Jameson SC, Hogquist KA. Positive and negative selection of T cells. Annu Rev Immunol 2003;21:139-76.

39. Fan T, Lu H, Hu H, Shi L, McClarty GA, Nance DM, et al. Inhibition of apoptosis in chlamydia-infected cells: blockade of mitochondrial cytochrome c release and caspase activation. J Exp Med 1998 Feb 16;187(4):487-96.

40. Greene W, Xiao Y, Huang Y, McClarty G, Zhong G. Chlamydia-infected cells continue to undergo mitosis and resist induction of apoptosis. Infect Immun 2004 Jan;72(1):451-60.

41. Dean D, Powers VC. Persistent Chlamydia trachomatis infections resist apoptotic stimuli. Infect Immun 2001 Apr;69(4):2442-7.

42. Jorgensen I, Bednar MM, Amin V, Davis BK, Ting JP, McCafferty DG, et al. The Chlamydia protease CPAF regulates host and bacterial proteins to maintain pathogen vacuole integrity and promote virulence. Cell Host Microbe $2011 \mathrm{Jul}$ 21;10(1):21-32.

43. Pirbhai M, Dong F, Zhong Y, Pan KZ, Zhong G. The secreted protease factor CPAF is responsible for degrading pro-apoptotic $\mathrm{BH} 3$-only proteins in Chlamydia trachomatis-infected cells. J Biol Chem 2006 Oct 20;281(42):31495-501.

44. Ying S, Fischer SF, Pettengill M, Conte D, Paschen SA, Ojcius $\mathrm{DM}$, et al. Characterization of host cell death induced by Chlamydia trachomatis. Infect Immun 2006 Nov;74(11):6057-66.

45. Dong F, Pirbhai M, Xiao Y, Zhong Y, Wu Y, Zhong G. Degradation of the proapoptotic proteins Bik, Puma, and Bim with Bcl-2 domain 3 homology in Chlamydia trachomatis-infected cells. Infect Immun 2005 Mar;73(3):1861-4.

46. Perfettini JL, Reed JC, Israel N, Martinou JC, Dautry-Varsat A, Ojcius DM. Role of Bcl-2 family members in caspase-independent apoptosis during Chlamydia infection. Infect Immun 2002 Jan;70(1):55-61.

47. Fischer SF, Schwarz C, Vier J, Hacker G. Characterization of antiapoptotic activities of Chlamydia pneumoniae in human cells. Infect Immun 2001 Nov;69(11):7121-9. 